\title{
Can You Get a Ticket? Adaptive Railway Booking Strategies by Customer Value
}

\author{
Jiana-Fu Wang, Ren-Huei Huang \\ National Chung Hsing University, Taiwan (ROC)
}

\begin{abstract}
This paper integrates a customer segmentation method with a discrete event simulation model to bridge the gap between identifying customer behaviors and using this knowledge to respond to customers and make the best use of resources. Three strategies are proposed and examined to improve the operation efficiency of a ticket-booking system. Their objective is to assist high-value customers in obtaining the tickets they want and/or reduce cancellations and failure-to-pays from low-value customers. Our simulation results demonstrate that the high-value, customer-friendly strategy beats all in assisting high-value customers and simultaneously improves railway operation performance. Additionally, the indirect, low-value customer abandonment strategy also has improved slightly in all aspects. Applying these strategies is expected to result in a decrease in complaints regarding booking system rejections and an increase in high-value customer satisfaction. On the other hand, the direct abandonment strategy to reject all low-value customers does not make any improvement.
\end{abstract}

Keywords: Railway, Booking, Simulation, Customer value, Customer segmentation, Customer relationship management

\section{Introduction}

Railway companies, with the popularity of e-booking systems, now have access to information on individual customer behaviors. This advantage can enable railway companies to initiate customer relationship management, or CRM, for improved profitability and resource allocation (Venkatesan and Kumar 2004; Kumar and Peterson 2005). According to Stringfellow et al. (2004), the intention of CRM is "understanding customer needs and leveraging that knowledge to improve a company's long-term profitability." Railway companies, due to traveler anonymity and the public nature of railway services, had no way to record customer purchase history in the past and could not differentiate their treatments to customers. Currently, with an e-booking system to 
retain individual customer data, railway companies can analyze each customer's value and allocate resources accordingly.

Utilizing individual customer purchase data to predict quantities of cancellations and no-shows has been confirmed effective in the field of airline research, as illustrated in the work of Lawrence et al. (2003), Garrow and Koppelman (2004), Neuling et al. (2004), Gorin et al. (2006), and Illiescu et al. (2008). Similar research has been conducted in the railway system, but as far as the authors are aware, there are only the works of Cirillo et al. (2011), Hetrakul and Cirillo (2013), Piening et al. (2013), Hetrakul and Cirillo (2014), and Chen and Wang (2013). However, these two fields are still focused on applying their results to decide the amount of seat overbookings and the allocations of seats among different fare classes, rather than identifying an individual's value to decide how to respond to the individual's request.

Train seating is a valuable resource to a railway company. When a ticket is booked but not yet paid for, the slot is blocked from booking for other customers. Although loyal customers always pay for their booked tickets during the advance ticket-booking period, some ticket holders often hold their reservations for a period of time, frequently cancelling them subsequently. More than $40 \%$ of railway ticket bookings ultimately are cancelled in India, Taiwan, and China, according to Bharill and Rangaraj (2008), Chen and Wang (2013), and China Review News (2013), respectively. Not only does this highcancellation situation affect the booking system's operational efficiency, it also incurs complaints about people's inability to book tickets (Zhang et al. 2007; Von Martens and Hilberts 2011). If a customer's booking is rejected because slots are fully booked, yet some or part of those booked slots are eventually cancelled and later booked by others, the customer may be resentful. A loyal customer, frustrated by repeated booking failures, might switch to a competing provider to make his journey possible. This becomes a "lose-lose" situation for both customers and the railway company.

A company should recognize the profitability of loyal customers from the CRM perspective and attempt to know their functional and emotional needs (Stringfellow et al. 2004): they need tickets, and they think they have a priority in making reservations. On the other hand, the company should consider abandoning those who consume a railway company's resources and damage its performance, who may be labeled as "troublemakers" (Van Raaij 2005; Haenlein and Kaplan 2009; Haenlein and Kaplan 2011). The direct abandonment of troublemakers may cause most companies to hesitate; yet, some indirect abandonment strategies can lead to less severe reactions from customers, such as increasing prices and decreasing service levels (Haenlein and Kaplan 2011; Haenlein and Kaplan 2012).

This study aims to use individual-level booking data to implement CRM strategies to improve the performance of a railway ticket booking system. Customers are segmented into three groups, based on a Taiwanese railway agency's ticket booking database. Three strategies then concentrate on assisting high-value customers to obtain tickets, applying an indirect abandonment policy to low-value customers, and using a direct abandonment policy to reject low-value customers in comparison with a base scenario to evaluate their effectiveness. The remainder of the paper is organized as follows: First, 
literature on passenger name record (PNR) applications in ticket booking, customer value analysis, and customer management is reviewed. Next, the development of customer segmentation and ticket booking simulation models is introduced. Finally, the implementing of models and conclusions are presented.

\section{Using PNR in Ticket-Booking Services}

Early ticket booking papers in railway and airline services primarily utilize aggregated booking data to forecast demand, predict cancellations and no-shows, and allocate seats to various legs and classes. With an increasing number of customer booking databases and improvements in computer calculation speed, a new trend involves utilizing PNRs to increase prediction accuracy (Garrow and Koppelman 2004; Morales and Wang 2010). A PNR is generated when a ticket booking is made. Its typical information includes time of service, time of booking, time of cancellation, ticket type/ fare by class, membership, payment status, origin and destination, reservation channel, group size, day(s) of travel, and number of travel legs, for air travel providers. By using PNRs, customers are heterogeneous agents with their own features, and they interact with others to exhibit aggregate behavior (Khouja et al. 2008).

The application of PNR in ticket booking can be classified into three categories. The first category uses discrete choice models that originate from Talluri and Van Ryzin's (2004) research. Garrow and Koppelman (2004) developed a multinomial logit (MNL) model for the airline industry to predict the percentages of show, cancellation, no-show, and standby for each potential traveler. They concluded that the incorporation of passenger information can improve forecasting accuracy. lliescu et al. (2008) described a booked ticket's cancellation as a survival process, and the survival percentage of each booking relied on the reservist's characteristics. Graham et al. (2010) used a discrete-time proportional odds model to predict the conditional probability of a ticket surviving from one period to the next. Similar techniques are also applied in the railway industry. Hetrakul and Cirillo (2013) applied three logit-based ticket purchase timing models and compared their suitability to three market segments with different travel distances. Additionally, Piening et al. (2013) analyzed customer choices to upgrade, downgrade, or cancel their ticket discount cards when their cards were due. Their hazard model identified several CRM practices that would affect the discount cards' renewal.

The second category applies data mining techniques to explore meaningful relationships in the customer-booking database. Lawrence et al. (2003) demonstrated that their three data-mining models employing PNRs were superior to a historical model in forecasting airline no-shows. Neuling et al. (2004) introduced how Lufthansa German Airlines applied a decision tree-based model to forecast no-show probabilities. Morales and Wang (2010) tested three decision tree-based models using hotel booking data and found that compared to several traditional statistical methods, they could reduce a $20 \%$ forecast error. Its application in the railway industry was developed by Chen and Wang (2013), who used a two-stage clustering model to predict customer values and recommended loyalty program strategies for each customer group. 
The final category employs combinatorial methods to forecast customer behavior. Gorin et al. (2006) developed a cost-based, PNR-adjusted approach to find optimal no-show rates for the airline industry. Their objective was to minimize the cost of seat overselling and underselling, while adjusting its no-show probabilities for different customer segments using historical booking data. They concluded that the new approach could improve revenue by up to $10 \%$ compared to traditional average no-show rate methods. Cirillo et al. (2011) established an MNL model for the railway industry to explain passengers' choice of booking time, and combined it with a linear-regression demand function to find optimal fares. Hetrakul and Cirillo (2014) further used their logit and demand models to jointly decide optimal ticket prices and seat allocations.

It can be asserted from the above reviews that PNR studies in ticket booking are limited, and the purpose of these studies is primarily to aggregate predicted individual behaviors as parameters to estimate total number of demands, cancellations, or no-shows. The premium benefit of analyzing PNR is not only to predict what might occur, but also to guide a company's actions (Lavalle et al. 2011). The evident link between identifying customer behaviors and using this knowledge to respond to customers is still lacking in ticket-booking literature.

\section{Customer Value Analysis and Customer Management}

Several innovative companies have acknowledged that providing differentiated services to customers based on their profitability can be more beneficial, as resources are limited and valuable. For example, investing in the top 1\% of customers could earn 50\% of a company's revenue, but serving the bottom $20 \%$ could cost the company money (Ziethaml et al. 2001; Van Raaij 2005). Therefore, identifying customer value and treating them appropriately is an important avenue for becoming a top performing company.

Customer value can be assessed either by solely using past purchase history or by forecasting future cash flow. The former can be calculated by applying recency, frequency, and monetary (RFM), activity-based costing, past customer value, and shareof-wallet methods (Kumar 2006). The latter is based primarily on the customer lifetime value (CLV) concept proposed by Jackson (1989), a prediction of the net discounted profit obtained from a customer over his or her lifetime with a company. This considers when and how much the customer will purchase, and how the company will invest its resources. A prediction of CLV can be obtained via different types of models, such as the negative binomial distribution (NBD)/Pareto model, the beta-geometric/NBD model, and hazard models (Fader et al. 2005; Gupta et al. 2006).

The RFM method has been used the most frequently among these methods for decades to select customers (Bijmolt et al. 2010). Its fundamental rationale is that those who have recently made purchases, make more repeated purchases, and spend more money are a company's best customers (McCarty and Hastak 2007). Variables other than the original $R, F$, and $M$ are incorporated in extended studies. For example, Wei et al. (2012) added "relation length" and Khajvand et al. (2011) proposed "count item" in their models. Although CLV is an effective tool to measure direct, or transactional 
contributions, it overlooks the non-monetary benefit or harm that customers may carry. As this paper considers customer cancellation and no-show (or failure-to-pay, in the railway scenario) behaviors, an extended RFM model is utilized to segment customers. Therefore, in this study, customer value is defined as the direct and indirect contributions brought by a customer to a company during a period of time (von Martens and Hilbert 2011).

Once customers are categorized by their values, companies can allocate resources differently by group. For example, Reinartz and Kumar (2002) segment customers into four types - true friends, barnacles, butterflies, and strangers - and suggest that companies should implement differentiated strategies for these groups. These strategies include communicating consistently and finding ways to increase the loyalty of "true friends"; promoting up- and cross-selling or controlling costs for "barnacles"; preparing to cease investment in "butterflies"; and making no investment in "strangers." Likewise, First Union, a US bank, provides extra customer service support to its profitable customers, but it does not grant special favors, such as waiving bounced checks, to those who are unprofitable (Zeithaml et al. 2001). In 2007, Sprint Nextel terminated wireless services to approximately 1,000 customers for making "too many" service calls, with some amounting to hundreds per month (Mittal et al. 2008). Filene's Basement, a retailer, curtailed all further service to two sisters in 2003 because of their chronic complaints and returning of goods (Haenlein and Kaplan 2009). These cases demonstrate that halting resources, or even abandoning unprofitable or low-value customers, exists in practice.

Although abandoning a customer is not an easy decision for any company, it is considered based on the following reasons: customer profitability, employee productivity, capacity constraint, and target market (Mittal et al. 2008). If a company must abandon a customer, there are direct and indirect abandonment strategies. A direct abandonment strategy refers to a situation in which a company explicitly expresses the intention to end the relationship with the customer, such as the Sprint Nextel and Filene's Basement cases. On the other hand, a company may choose an indirect abandonment strategy, which terminates the relationship with a customer without explicitly communicating this to the customer (Haenlein and Kaplan 2011). According to Haenlein and Kaplan (2011; 2012), divesting unprofitable or low-value customers can prevent future losses and may improve a company's image among some types of current customers. However, in the meantime, the company may risk negative word-of-mouth (WOM). Therefore, carefully designing abandonment strategies and managing potential reactions become important.

\section{Model Development}

\section{Customer Segmentation Model}

Two models were developed during this research for identifying customer values using PNRs and measuring the effectiveness of booking strategies for a railway ticket 
booking system in Taiwan. The ticket booking system stores personal ID, date and time of booking, train number, trip origin, trip destination, order quantity, and status, such as purchased, cancelled, or failure-to-pay, for each booking record. Six variables were extracted from these booking data to constitute an extended RFM model.

1. Recency $(R)$ - the interval between when a customer last booked and the end of a specified period of time.

2. Frequency $(F)$ - the number of bookings during a specified period of time.

3. Monetary $(M)$ - the average amount of money a customer spends for each booking during a specified period of time, not including cancelled and failure-topay bookings.

4. Total Mileage (TM) - the total mileage traveled during a specified period of time, not including the mileages of other passenger(s) travelling along with the customer.

5. Purchase Rate (PR) - the purchase rate of a customer's total bookings during a specified period of time.

6. Average Status Score (ASS) - the average status score of the bookings from a customer during a specified period of time ( 5 points for a purchased booking, 3 points for a cancelled booking, and 1 point for a failure-to-pay booking).

The customers in the booking database are assigned a number from 5 to 1 , according to their rankings for each of the three variables, using the procedure proposed by Hughes (1994). These customers are then grouped by their summed scores. The higher a customer's summed score, the more beneficial the customer is to the company in terms of their loyalty in making repeated purchases and paying for their booked tickets. On the other hand, those who have low scores are labeled as "troublemakers" who consume booking resources and block other customers' reservations but seldom pay for their bookings.

\section{Ticket Booking Simulation Model}

A discrete event simulation model is built as the schema in Figure 1, in accordance with actual ticket-booking processes. The model originates with a potential passenger's arrival and request for ticket(s) at the system. The potential passenger is mapped to the properties of a randomly drawn customer from our database, which is based on real customer booking records, to imitate the customer's behavior. If the potential passenger's request for a specific travel section (origin-destination pair, O-D pair) and number of tickets can be met, the booking is accepted. If not, the customer may possibly return to the system the next day for another attempt. The customer's choosing to make a further attempt depends on the customer's rebooking intention. After a booking, one of three possible follow-up actions may occur within a deadline: purchase, cancellation, or failure-to-pay. The customer's action depends on the probabilities of his or her past behavior. If the booking is cancelled, or if there is a failure-to-pay within the deadline, the ticket(s) will be released for subsequent possible booking. However, if the booking is paid for, the booking process is completed. 
FIGURE 1.

Base model for ticket-booking

processes

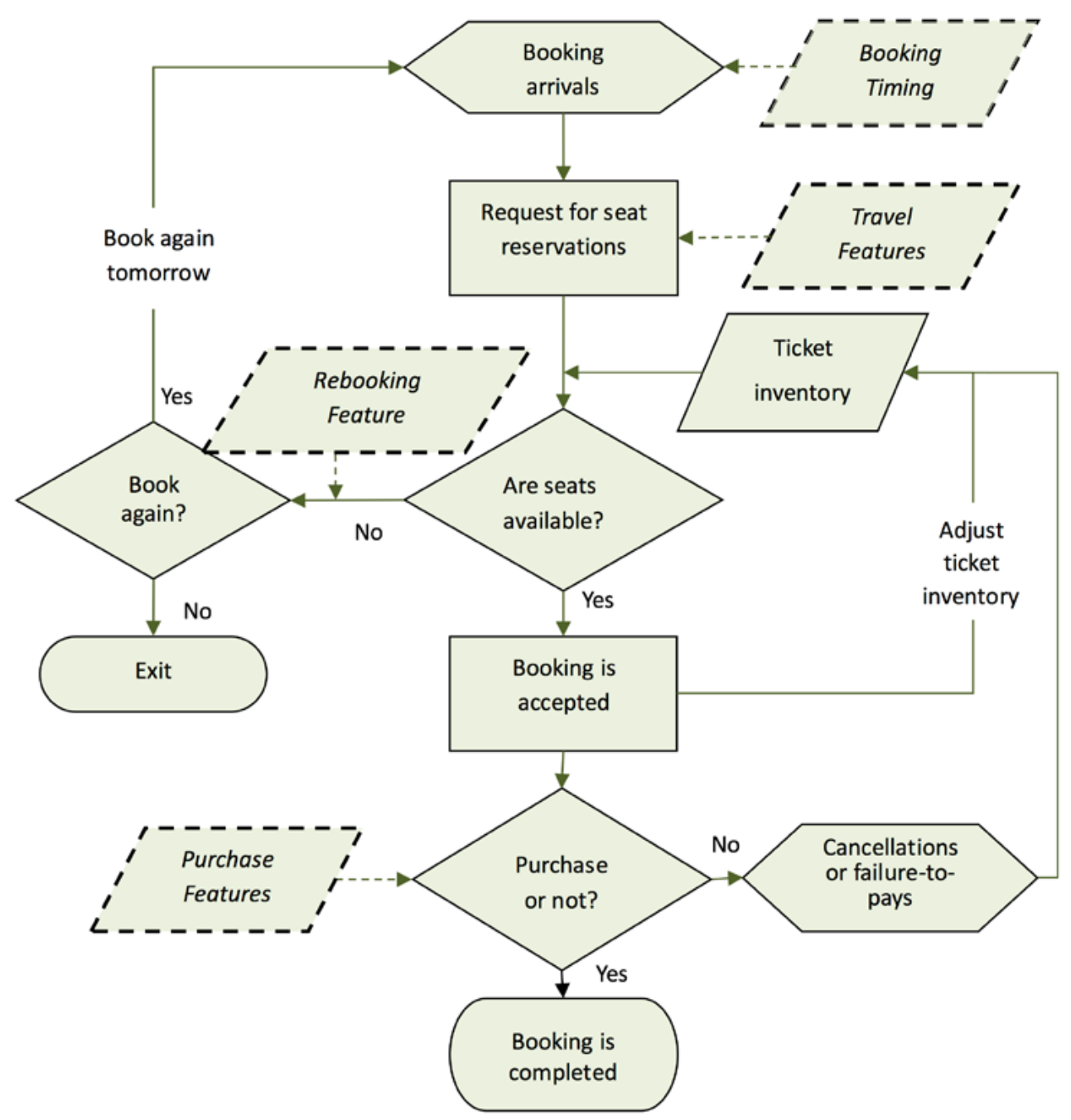

Among the aforementioned processes, four decision points exist at which a customer's personal characteristics, or behaviors, are considered. The relevant characteristics are "booking timing," "travel features," "rebooking intention," and "purchase features," as noted in Figure 1. The interactions between booking processes and personal actions not only impact the inventory of tickets, but also comprise the dynamics of the ticket booking system. PNRs were collected and managed, as listed in Table 1, to obtain these personal characteristics. 
TABLE 1.

Contents and Specifications of Customer Characteristics

\begin{tabular}{|c|c|c|}
\hline \multicolumn{2}{|c|}{ Personal Characteristics } & Characteristic Specification Method \\
\hline \multirow{2}{*}{$\begin{array}{l}\text { Booking } \\
\text { timing }\end{array}$} & $\begin{array}{l}\text { Customer } \\
\text { segment }\end{array}$ & $\begin{array}{l}\text { Customers categorized into several different segments by RFM } \\
\text { analysis }\end{array}$ \\
\hline & Customer arrival & $\begin{array}{l}\text { Segments' inter-arrival times for each booking day tallied to build } \\
\text { their arrival distributions }\end{array}$ \\
\hline \multirow{2}{*}{$\begin{array}{l}\text { Travel } \\
\text { features }\end{array}$} & Traveling section & O-D pair most frequently traveled by customer \\
\hline & $\begin{array}{l}\text { Number of tickets } \\
\text { booked }\end{array}$ & Rounded average number of tickets booked each time by customer \\
\hline $\begin{array}{l}\text { Rebooking } \\
\text { intention }\end{array}$ & Rebooking rate & $\begin{array}{l}\text { Number of bookings for this train as percentage of total bookings } \\
\text { (for all trains); this ratio displays train's importance to customer - } \\
\text { the higher the ratio, the more likely that the customer will attempt } \\
\text { to make bookings again; there are two maximum attempts to rebook } \\
\text { in this study }\end{array}$ \\
\hline \multirow{3}{*}{$\begin{array}{l}\text { Purchase } \\
\text { features }\end{array}$} & Purchase rate & Number of purchases as percentage of total bookings \\
\hline & Cancellation rate & Number of cancellations as percentage of total bookings \\
\hline & Failure-to-pay rate & Number of failure-to-pays as percentage of total bookings \\
\hline
\end{tabular}

\section{Ticket-Booking Strategies}

The purpose of this study was to propose strategies to improve a ticket booking system's efficiency by helping high-value customers obtain the tickets they want or/ and reducing troublemakers to incur cancellations and failure-to-pays. To meet this objective, we proposed one high-value customer-friendly strategy and two low-value customer abandonment strategies and evaluated their performances along with the base model.

1. High-value customer-friendly strategy: flexible booking limits (FBL) - The goal with this strategy is to facilitate high-value customer bookings by combining two or more available O-D pairs to turn into an O-D pair that the customer had failed to obtain initially because it had been fully booked. Normally, a train's seat allocation is fixed. The disadvantage of a fixed booking limit policy is that it can cause considerable inefficiency when demands are stochastic (Talluri and Ryzin 2004). Hence, when some O-D pairs are fully booked, others may still have vacant seats. High-value customers are reliable, loyal, and profitable for a company; helping them obtain bookings not only raises their satisfaction, but also increases ticket bookings' overall purchase rate.

2. Indirect abandonment strategy: overbooking $(\mathrm{OB})$ - The objective with this strategy is to borrow booked tickets from low-value customers, who have a low purchase rate, and lend them to high-value customers. This method is similar to the airline industry's overbooking strategy. It still provides booking services to low-value customers initially, but these booked seats will be taken away if and once they are cancelled and transferred to overbooked high-value customers. It is expected that this strategy will increase the booking success rate of high-value customers, and lower the overall cancellation rate. 
3. Direct abandonment strategy: rejecting low-value customers (RLC) - Although it is difficult to implement in real life, this study builds an extreme strategy to reject all bookings from low-value customers, to observe its impact. When a low-value customer wants to make a booking, the customer will be rejected. This strategy is expected to increase the overall purchase rate, and reduce cancellation and failure-to-pay rates.

4. Base model - The base model follows the booking processes illustrated in Figure 1 and is basically a first-come-first-served scenario. Whether or not a customer obtains tickets is based on both the order of arrival and the availability of seats in the desired O-D pair.

\section{Simulation Results}

\section{Experimental Design}

The Taiwan Railway Administration (TRA) is the largest railway operator in Taiwan. In its booking system, ticket fares are fixed during its 14-day booking period. A customer can book up to 6 tickets for a train. Customers who book in the system have to make their payments or cancel their bookings (free of charge) before the end of the next day or the booked tickets will be released. An analysis was performed to apply the extended RFM method; 332,584 customers with booking records on TRA's Western Main Line during the period of August 1-October 31, 2010, were analyzed, with their scores ranging from 6 to 30 points. Further, this study chose the customers who booked Train Number $X$ (the identity of the train number is disguised for confidentiality reasons) during this period as subjects to extract their personal characteristics, as mentioned in Table 1, to use in the simulation model. During this period, there were 13,635 passengers who made 32,647 reservations for Train Number X, and in total they made 186,186 reservations from all 228 trains operated by the TRA. Among these passengers, 725 were graded 6-9 points and 766 were graded $29-30$ points. As the number of target customers who are given favors or abandoned should not excessively distort TRA's daily operations, these two groups were defined as low-value and high-value customers, while the others were categorized as regular customers. The results in Table 2 exhibit the differences among the three customer segments, showing that low-value customers never pay for their booked tickets, and most tend to cancel their bookings; the highvalue customers have a high purchase rate, and they spend and travel more than others.

Averages of Variables for Three Customer Segments

\begin{tabular}{|l|c|c|c|c|c|c|c|}
\hline \multicolumn{1}{|c|}{ Segment } & $\begin{array}{c}\text { Number of } \\
\text { Customers }\end{array}$ & $\begin{array}{c}\text { R } \\
\text { (day) }\end{array}$ & $\begin{array}{c}\text { F } \\
\text { (times) }\end{array}$ & $\begin{array}{c}\text { M } \\
(\mathbf{\$})\end{array}$ & $\begin{array}{c}\text { TM } \\
(\mathbf{m i})\end{array}$ & $\begin{array}{c}\text { PR } \\
(\%)\end{array}$ & $\begin{array}{c}\text { ASS } \\
\text { (point) }\end{array}$ \\
\hline High-value customer & 776 & 21 & 16 & 17 & 1801 & $90 \%$ & 4.76 \\
\hline Regular customer & 12,134 & 41 & 14 & 10 & 695 & $51 \%$ & 3.74 \\
\hline Low-value customer & 725 & 75 & 2 & 0 & 0 & $0 \%$ & 2.22 \\
\hline Total & 13,635 & & & & & & \\
\hline
\end{tabular}

$R=$ Recency $F=$ Frequency $M=$ Monetary; $T M=$ Total Mileage; $P R=$ Purchase Rate; ASS $=$ Average Status Score 
The original Train Number $\mathrm{X}$ had 18 stops, which gave 153 possible combinations (that is, $C_{2}^{18}$ ) for seat allocations. However, 5 stops were adopted to simplify the situation, as were 10 combinations (O-D pairs). Figure 2 illustrates seat allocations for the train.

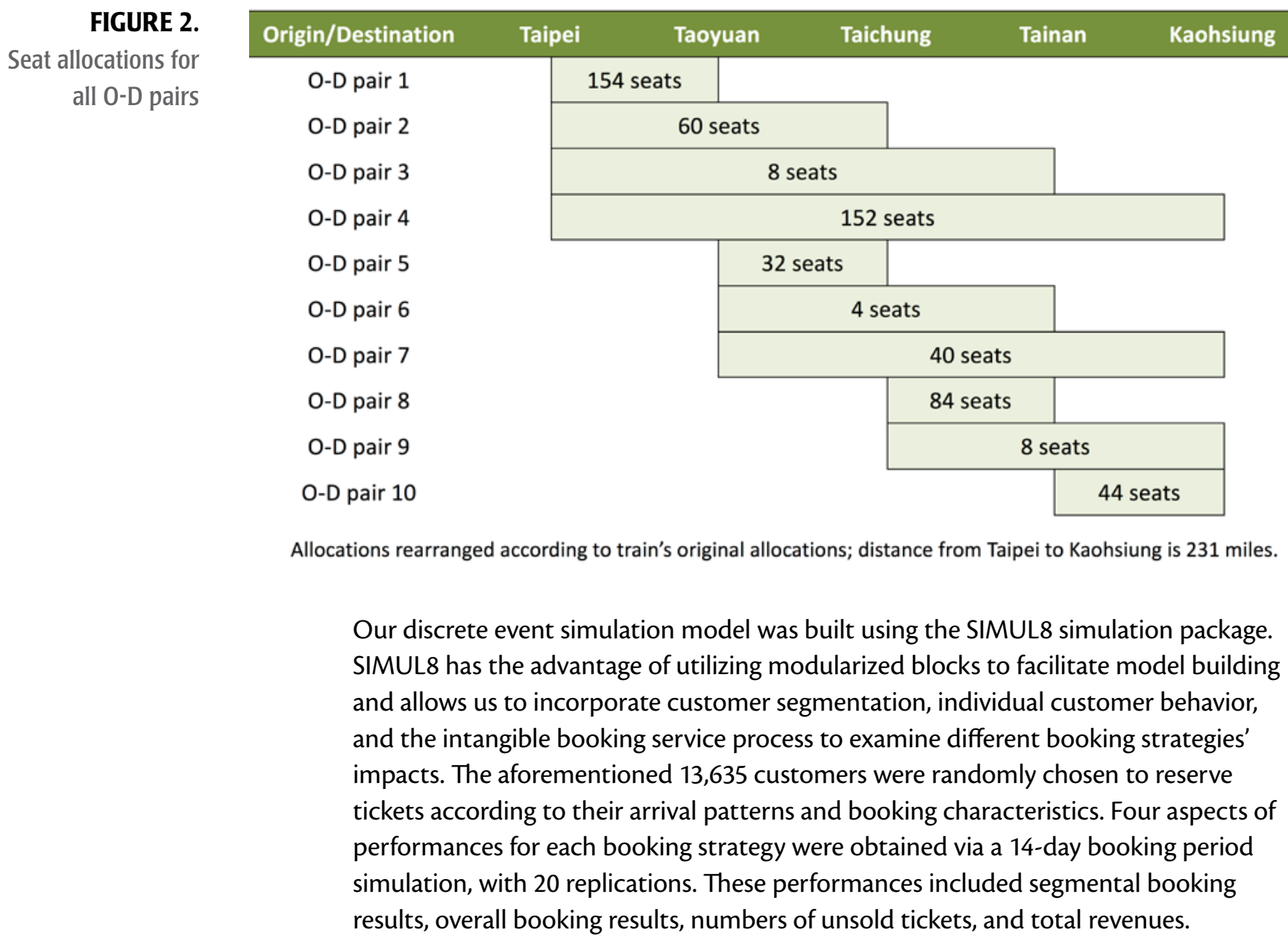

\section{Segmental Booking Results}

The results in Table 3 illustrate that the booking success rates of high-value customers with the first three strategies were all increased compared to the base model. The FBL strategy especially had the largest improvement (from $27.42 \%$ to $68.99 \%$ ), and the success rates in the other two segments did not decrease. This advantage came from the reduction of booking failures by searching combinable tickets for high-value customers. The OB strategy had a smaller improvement (from $27.42 \%$ to $35.33 \%$ ) and did not affect the other two segments' success rates. On the other hand, the RLC strategy, which blocks all bookings from low-value customers, also generated marginal improvements in the high-value and regular customer segments.

Additionally, the numbers of purchased tickets with the proposed three strategies were all increased, indicating that they can help increase ticket sales. One thing to note in Table 3 is that low-value customers have higher booking success rates in the FBL, OB, 
and Base strategies. It is because low-value customers tend to book tickets earlier during the booking period compared to regular and high-value customers in our database and, therefore, have higher chance to get reservations.

TABLE 3.

Booking Results by Segment

\begin{tabular}{|c|c|c|c|c|c|c|c|}
\hline \multirow{2}{*}{ Strategy } & \multirow{2}{*}{$\begin{array}{l}\text { Customer } \\
\text { Segment }\end{array}$} & \multicolumn{3}{|c|}{ Able to Book } & \multirow{2}{*}{$\begin{array}{l}\text { Failure } \\
\text { to Book }\end{array}$} & \multirow{2}{*}{ Total } & \multirow{2}{*}{$\begin{array}{c}\text { Booking } \\
\text { Success Rate }\end{array}$} \\
\hline & & Cancellation & Failure-to-Pay & Purchase & & & \\
\hline \multirow{4}{*}{ FBL } & High & 20 & 5 & 73 & 44 & 142 & $69 \%$ \\
\hline & Regular & 208 & 74 & 213 & 1,041 & 1536 & $32 \%$ \\
\hline & Low & 43 & 18 & 0 & 70 & 131 & $47 \%$ \\
\hline & Total & 271 & 97 & 286 & 1,155 & 1,809 & $36 \%$ \\
\hline \multirow{4}{*}{$\mathrm{OB}$} & High & 10 & 3 & 37 & 91 & 141 & $35 \%$ \\
\hline & Regular & 205 & 75 & 210 & 1,046 & 1,536 & $32 \%$ \\
\hline & Low & 41 & 18 & 0 & 71 & 130 & $45 \%$ \\
\hline & Total & 256 & 96 & 247 & 1,208 & 1,807 & $33 \%$ \\
\hline \multirow{4}{*}{ RLC } & High & 8 & 2 & 30 & 100 & 140 & $29 \%$ \\
\hline & Regular & 208 & 76 & 213 & 1,038 & 1,535 & $32 \%$ \\
\hline & Low & 0 & 0 & 0 & 176 & 176 & $0 \%$ \\
\hline & Total & 216 & 78 & 243 & 1,314 & 1,851 & $29 \%$ \\
\hline \multirow{4}{*}{ Base } & High & 7 & 2 & 29 & 101 & 139 & $27 \%$ \\
\hline & Regular & 204 & 74 & 208 & 1,050 & 1,536 & $32 \%$ \\
\hline & Low & 41 & 18 & 0 & 73 & 132 & $45 \%$ \\
\hline & Total & 252 & 94 & 237 & 1,224 & 1,807 & $32 \%$ \\
\hline
\end{tabular}

\section{Overall Booking Results}

The overall booking success rates with $\mathrm{FBL}$ and $\mathrm{OB}$ strategies were higher than the rate in the base model, as noted in Table 3. This means that all customers can benefit from these two strategies helping high-value customers obtain tickets, and the TRA can simultaneously increase customer booking satisfaction.

Further, paired t-tests were used to compare the results of the Base model with other strategies to determine whether the differences are significant. As demonstrated in Table 4, the total number of booking successes (able-to-books) was significantly increased except for the RLC strategy. The reduction in the case of RLC occurred mainly because of the increase in booking rejections by low-value customers. If the possible consequences of successful bookings are considered, it can be noted that purchase rates with the first three strategies were significantly increased, and cancellation and failure-to-pay rates in the cases of FBL and RLC all decreased. This implies that overall efficiency improved, either because of boosting bookings from high-value customers or restraining bookings from low-value customers. 
TABLE 4.

Overall Booking Results

\begin{tabular}{|l|c|c|c|c|}
\hline \multirow{2}{*}{ Strategy } & \multicolumn{4}{|c|}{ Able to Book } \\
\cline { 2 - 5 } & Cancellation & Failure-to-Pay & Purchase & Total \\
\hline FBL & $270^{*}\left(41.4 \%^{*}\right)$ & $96^{\Delta}\left(14.7 \%^{*}\right)$ & $286^{*}\left(43.9 \%^{*}\right)$ & $652^{*}(100 \%)$ \\
\hline OB & $256\left(42.8 \%^{\Delta}\right)$ & $95(15.9 \%)$ & $247^{*}\left(41.3 \%^{* *}\right)$ & $598^{* *}(100 \%)$ \\
\hline RLC & $216^{*}\left(40.4 \%^{*}\right)$ & $77^{*}\left(14.4 \%^{*}\right)$ & $242^{* *}\left(45.2 \%^{*}\right)$ & $535^{*}(100 \%)$ \\
\hline Base & $252(43.2 \%)$ & $94(16.1 \%)$ & $237(40.7 \%)$ & $583(100 \%)$ \\
\hline
\end{tabular}

* Significantly different from result of Base strategy; $p<0.001$.

** Significantly different from result of Base strategy; $p<0.01$.

${ }^{\Delta}$ Significantly different from result of Base strategy; $p<0.1$.

Table 5 displays the averages of unsold tickets and corresponding mileages for the 10 travel O-D pairs at the end of the 14-day booking period. The unbalanced results of unsold tickets among these O-D pairs were due to the mismatch of seat allocation and real customer demand, which challenges all kinds of service providers. The FBL strategy was proposed because of this mismatch, to reduce the imbalance. The results in Table 5 confirm the effectiveness of FBL strategy; excess seats from some O-D pairs were added to enable the completion of bookings from high-value customers and thus, more tickets can be sold. The other two strategies do not aim to increase ticket selling. Therefore, these quantities of unsold tickets and mileages do not significantly differ from the base model.

TABLE 5.

\begin{tabular}{|l|c|c|c|c|c|c|c|c|c|c|c|c|}
\hline $\begin{array}{c}\text { O-D } \\
\text { Pair }\end{array}$ & $\mathbf{1}$ & $\mathbf{2}$ & $\mathbf{3}$ & $\mathbf{4}$ & $\mathbf{5}$ & $\mathbf{6}$ & $\mathbf{7}$ & $\mathbf{8}$ & $\mathbf{9}$ & $\mathbf{1 0}$ & Total & $\begin{array}{c}\text { Unsold } \\
\text { Mileage (mi) }\end{array}$ \\
\hline FBL & 114.3 & 1.8 & 0.7 & 6.4 & 1.2 & 0.3 & 1.1 & 38.3 & 0.7 & 8.1 & $173.0^{*}$ & $8,391^{*}$ \\
\hline OB & 118.0 & 1.7 & 0.8 & 5.7 & 1.3 & 0.6 & 0.7 & 65.2 & 0.1 & 34.4 & 228.4 & 11,642 \\
\hline RLC & 122.2 & 1.0 & 0.5 & 6.5 & 1.3 & 0.5 & 0.7 & 65.4 & 0.2 & 34.2 & $232.4^{* *}$ & 11,779 \\
\hline Base & 118.1 & 0.8 & 1.0 & 6.7 & 0.8 & 0.4 & 1.1 & 65.4 & 0.1 & 34.6 & 229.0 & 11,854 \\
\hline
\end{tabular}

* Significantly different from result of Base strategy; $p<0.001$.

** Significantly different from result of Base strategy; $p<0.1$.

Total revenue for the above four strategies can be calculated from the prices and numbers of sold tickets. Their average revenues are $\$ 7,287, \$ 6,892, \$ 6,874$, and $\$ 6,865$, respectively. The results demonstrate that the FBL strategy again exhibited more improvement (6.1\%), whereas OB and RLC strategies did not significantly differ from the base model.

\section{Conclusions}

From a business management perspective, as the best customers are more loyal and profitable, managers should always maintain a good relationship with them, even if it sometimes may be necessary to sacrifice low-value customers' benefits. However, the literature review reveals a gap in the railway industry's linkage between customer value analysis and a corresponsive CRM strategy. Concerning this inadequacy, this study provided an example of identifying customer profitability, implementing 
differentiated strategies for tiered customers, and demonstrating the effectiveness of the differentiated strategies. Through PNR analysis and comprehensive simulation experiments, the following important observations are made.

First, it can be observed that booking strategies responsive to high-value customers are effective. FBL strategy has the best potential to assist high-value customers and simultaneously improves operational performance. Its booking success rate with highvalue customers is up $156 \%$ (from $27 \%$ to $69 \%$, as shown in Table 3 ), overall booking success rate is up $13 \%$ (from $32 \%$ to $36 \%$, as shown in Table 3), overall purchase rate is up $8 \%$ (from $40.7 \%$ to $43.9 \%$, as shown in Table 4), number of unsold tickets is down by 24\% (from 229 to 173 tickets, as shown in Table 5), and revenue is up 6\% (from $\$ 6,865$ to $\$ 7,287$ dollars). Additionally, the OB strategy also has slight improvements in all aspects. From booking efficiency and cost-saving perspectives, as "it costs five times more to acquire a new customer than to retain an existing one" (Pfeifer 2005), a wise decision would be for railway managers to favor high-value customers.

Second, some managers may presume that a direct abandonment strategy to reject unprofitable customers is beneficial for their businesses, but that effect is not clearly supported by this study. The RLC strategy has minor improvements in high-value and regular customers' booking success rate, total purchase rate, and total revenue, but its total booking success rate, total number of successful bookings, and number of unsold tickets do not perform well. Although the RLC strategy provides more booking opportunities for regular and high-value customers, regular customers' greater quantity and lower purchase rate weaken this strategy's performance. This direct abandonment strategy does not improve booking efficiency, and risks inducing negative WOM and other costs (Mittal et al. 2008; Haenlein and Kaplan 2011); therefore, managers should consider educating and converting low-value customers to general customers rather than directly abandoning them.

Finally, the RFM analysis reveals that variations in customer booking behavior exist among different customer segments, and railway operators can benefit from allocating seat resources according to customer value. The model is especially applicable for air and railway transportation, which maintains booking data. Further, the concept of linking customer behavior and a company's operation strategy also can be employed in bus and metro transportation that does not own passenger identifications. For example, some transportation smart cards can be used to pay for parking fees, bike rentals, and store purchases, in addition to bus and metro fares. Cardholder travel data allows transport operators to know their customers' travel origins and destinations, when they travel, where they stop, and even what they purchase, and transport operators can arrange vehicle resources and advertising strategies accordingly. Along with the development of information technology, the applications of customer analytics to operation strategies will become more and more popular.

As with any research, this study has limitations. First, rebooking rates for rejected customers were estimations in this study because the actual rejected booking data were not recorded by the TRA. More detailed customer booking behavior could be explored were these data available. Second, the costs of customer rejection, cancellation, 
and failure-to-pays are difficult to quantify and, hence, were not considered. Future extensions can focus on the appraisal of these costs. Third, possible reactions to the customer-friendly and customer abandonment strategies are not considered, such as positive or negative WOM, or individual purchase rate increments.

\section{Acknowledgment}

The authors would like to acknowledge the valuable comments of three anonymous reviewers on an earlier version of this paper. The authors also thank the data provision from the TRA and the support from the Ministry of Science and Technology of Republic of China (No. NSC101-2410-H-005-060).

\section{References}

Bharill, R., and N. Rangaraj. 2008. "Revenue Management in Railway Operations: A Study of the Rajdhani Express, Indian Railways." Transportation Research Part A, 42: 11951207.

Bijmolt, T. H. A., P. S. H. Leeflang, F. Block, M. Eisenbeiss, B. G. S. Hardie, A. Lemmens, and P. Saffert. 2010. "Analytics for Customer Engagement." Journal of Service Research, 13(3): 341-356.

China Review News. 2013. "Ministry of Railways: $40 \%$ of Tickets Are Not Purchased. Seats May Be Available After 14:00." http://www.chinareviewnews.com. (in Chinese)

Chen, M. Y., and J. F Wang. 2013. "Mining TRA's Transaction Data for Loyalty Program Rules." Transportation Planning Journal, 42(3): 221-245.

Cirillo, C., P. Hetrakul, and S. Toobaie. 2011. “Discrete Choice Model for Amtrak Acela Express Revenue Management." Journal of Pricing and Revenue Management, 10(6): 492-513.

Fader, B. S., B. G. S. Hardie, and K. L. Lee. 2005. "'Counting Your Customers the Easy Way: An Alternative to the Pareto/NBD Model." Marketing Science, 24(2): 275-284.

Garrow, L. A., and F. S. Koppelman. 2004. "Predicting Air Travelers' No-show and Standby Behavior Using Passenger and Directional Itinerary Information." Journal of Air Transport Management, 10: 401-411.

Gorin, T., W. G. Brunger, and M. M. White. 2006. "No-show Forecasting: A Blended Costbased, PNR-adjusted Approach." Journal of Revenue and Pricing Management, 5(3): 188-206.

Graham R. J., L. A. Garrow, and J. D. Leonard. 2010. "Business Traveler's Ticketing, Refund, and Exchange Behavior." Journal of Air Transport Management, 16: 196-201.

Gupta, S., D. Hanssens, B. Hardie, W. Kahn, V. Kumar, N. Lin. N. Ravishanker, and S. Sriram. 2006. "Modeling Customer Lifetime Value." Journal of Service Research, 9(2): 139-155. 
Haenlein, M., and A. M. Kaplan. 2009. "Unprofitable Customers and Their Management." Business Horizons, 52: 89-97.

Haenlein, M. and A. M. Kaplan. 2011. "Evaluating the Consequences of Abandoning Unprofitable Customers: A Comparison of Direct and Indirect Abandonment Strategies." Zeitschrift Für betriebswirtschaft (Journal of Business Economics), 81: 77-94.

Haenlein, M., and A. M. Kaplan. 2012. "The Impact of Unprofitable Customer Abandonment on Current Customers' Exit, Voice, and Loyalty Intentions: An Empirical Analysis." Journal of Service Marketing, 26(6): 458-470.

Hetrakul, P., and C. Cirillo. 2013. "Accommodating Taste Heterogeneity in Railway Passenger Choice Models Based on Internet Booking Data." The Journal of Choice Modelling, 6: 1-16.

Hetrakul, P., and C. Cirillo. 2014. "A Latent Class Choice Based Model System for Railway Optimal Pricing and Seat Allocation." Transportation Research Part E, 61: 68-83.

Hughes, A. M. 1994. Strategic Database Marketing. Chicago: Probus publishing.

Illiescu, D. C., L. A. Garrow, and R. A. Parker. 2008. "A Hazard Model of US Airline Passengers' Refund and Exchange Behavior." Transportation Research Part B, 42: 229-242.

Jackson, D. 1989. “Determining a Customer's Lifetime Value." Direct Marketing, 51(11): 60-62+.

Khajvand M., K. Zolfaghar, S. Ashoori, and S. Alizadeh. 2011. "Estimating Customer Lifetime Value Based on RFM Analysis of Customer Purchase Behavior: Case Study." Procedia Computer Science, 3: 57-63.

Khouja, M., M. Hadzikadic, and M. A. Zaffar. 2008. "An Agent Based Modeling Approach for Determining Optimal Price-rebate Schemes." Simulation Modelling Practice and Theory, 16: 111-126.

Kumar, V. 2006. "Customer Lifetime Value." In The Handbook of Marketing Research: Uses, Misuses, and Future Advances, edited by R. Grover and M. Vriens, 602-627, Thousand Oaks: SAGE Publications, Inc.

Kumar V., and J. A. Peterson. 2005. "Using a Customer-level Marketing Strategy to Enhance firm Performance: A Review of Theoretical and Empirical Evidence." Journal of the Academy of Marketing Science, 33(4): 504-519.

Lavalle S., E. Lesser, R. Shockley, M. S. Hopkins, and N. Kruschwitz. 2011. "Big Data, Analytics and the Path from Insights to Value." MIT Sloan Management Review, 52: 20-32.

Lawrence, R. D., S. J. Hong, and J. Cherrier. 2003. "Passenger-based Predictive Modeling of Airline No-show Rates." In: Proc. of the Ninth ACM SIGKDD International Conference on Knowledge Discovery and Data Mining, 397-406, Washington D. C., USA. 
McCarty, J. A., and M. Hastak. 2007. "Segmentation Approaches in Data-mining: A Comparison of RFM, CHAID, and Logistic Regression." Journal of Business Research, 60: 656-662.

Mittal, V., M. Sarkees, and F. Murshed. 2008. "The Right Way to Manage Unprofitable Customers." Harvard Business Review, 86(4): 94-102.

Morales, D. R., and J. Wang. 2010. "Forecasting Cancellation Rates for Services Booking Revenue Management Using Data Mining." European Journal of Operational Research, 202: 554-562.

Neuling, R., S. Riedel, and K. Kalka. 2004. "New Approaches to Origin and Destination and No-show Forecasting: Excavating the Passenger Name Records Treasure." Journal of Revenue and Pricing Management, 3(1): 62-72.

Pfeifer, P. E. 2005. “The Optimal Ratio of Acquisition and Retention Costs." Journal of Targeting, Measurement and Analysis for Marketing, 13(2): 179-188.

Piening, J., T. Ehrmann and B. Meiseberg. 2013. “Competing Risks for Train Tickets - An Empirical Investigation of Customer Behavior and Performance in the Railway Industry." Transportation Research Part E, 51: 1-16.

Reinartz, W., and V. Kumar. 2002. "The Mismanagement of Customer Loyalty," Harvard Business Review, 80(7): 86-94.

Stringfellow, A., W. Nie, and D. E. Bowen. 2004. "CRM: Profiting from Understanding Customer Needs." Business Horizon, 47(5): 45-52.

Talluri, K. T., and G. J. van Ryzin. 2004. The Theory and Practice of Revenue Management, New York: Springer Science+Business Inc.

Van Raaij, E. M. 2005. "The Strategic Value of Customer Profitability Analysis." Marketing Intelligence \& Planning, 23(4): 372-381.

Venkatesan, R., and V. Kumar. 2004. "A Customer Lifetime Value Framework for Customer Selection and Resource Allocation Strategy." Journal of Marketing, 68:106125.

Von Martens, T., and A. Hilbert. 2011. "Customer-value-based Revenue Management." Journal of Revenue and Pricing Management, 10(1): 87-98.

Wei, J. T., S. Y. Lin, C. C. Weng, and H. H. Wu. 2012. "A Case Study of Applying LRFM Model in Market Segmentation of a Children's Dental Clinic." Expert Systems with Applications, 39: 5529-5533.

Zhang, Y., W. Fan, H. Chen, H. Sheng, and Z. Wu. 2007. "Extending Online Travel Agency with Adaptive Reservations." In Lecture Notes in Computer Science 4803, edited by R. Meersman and Z., Tari, 285-299, Heidelberg Springer-Verlag Berlin.

Zeithaml, V. A., R. T. Rust, and K. N. Lemon. 2001. "The Customer Pyramid: Creating and Serving Profitable Customers." California Management Review, 43(4): 118-142. 


\section{About the Authors}

JIANA-Fu WANG (jfwang@nchu.edu.tw) is an Assistant Professor of Marketing at National Chung Hsing University. He received a Ph.D. in Transportation Science from the University of California, Irvine. His areas of expertise are rail and metro transportation, supply chain and logistics management, e-commerce, customer analytics, and discrete event simulation. He has published several articles in these fields.

Ren-Hue HuANG (justtry0612@hotmail.com) received a master's degree in Marketing from National Chung Hsing University. 